\title{
Validity of Quarter-wavelength Approximation In the case of Tohoku-oki earthquake
}

\author{
Tao SHANG ${ }^{1, a}$, Zhengru TAO ${ }^{1, b^{*}}$, Baihui ZHU ${ }^{1, c}$, and Xiaxin TAO ${ }^{2, d}$ \\ ${ }^{1}$ Key Laboratory of Earthquake Engineering and Engineering Vibration \\ Institute of Engineering Mechanics, China Earthquake Administration, Harbin, China \\ ${ }^{2}$ School of Civil Engineering,Harbin Institute of Technology, Harbin, China

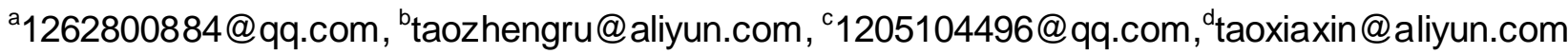 \\ * Corresponding author
}

\begin{abstract}
Keywords: site amplification; quarter-wavelength approximation; Fourier spectrum; Tohoku-oki. Abstract. Site amplification is important in ground motion prediction. It describes the effect of soil sites on ground motions. The quarter-wavelength approximation for computing site amplification has been developed for several decades. It is validated by the data from the main shock of 2011 Tohoku-oki Earthquake, recorded by KiK-net. A part of the site amplification factors obtained by quarter-wavelength approximation method are less than the actual amplification factors. The most ratios of the real amplification are smaller than 10, can more accurately reflect the true site amplification.
\end{abstract}

\section{Introduction}

To recognize site characteristics, site amplifications are needed, which are also important to correct observed data or predicted ground motion from different sites. There are several ways to evaluate the site amplification.

Velocity profile is measured to understand in details, which is a thorough approach with the physical properties. However, the high cost of borehole logging makes it uneasy. In most cases, relevant physical properties are not a vailable, it is necessary to develop practical and reliable methods. Standard spectral ratio method, which is introduced by Borcherdt in 1970 [1], is the mean of the ratios of soil site records to reference rock site records on surface. It is not easy to locate the reference site. Another method is the horizontal to vertical (H/V) spectral ratio, which is introduced by Nakamura in 1989 [2]. An alternative method compares observed records with those expected by $\omega^{2}$ source model, which is a combination of physical modeling and statistical approach [3].

Joyner et al. introduced the quarter-wavelength approximation to compute the site amplification in 1981 [4], and Boore and Joyner considered the amplifications was based on shear velocity and density as functions of depth [5]. The amplifications can be used directly in the stochastic model for simulating earthquake ground motions, which are computed by the quarter-wavelength approximation.

Records from 2011 Tohoku-oki Earthquake, recorded by KiK-net, are adopted to validate the application of the quarter-wavelength approximation. The effects of source and path are avoided, and the site amplification is our focus.

\section{Database}

KiK-net (Kiban Kyoshin network) is a strong-motion seismograph network, which consists of pairs of seismographs installed in a borehole and on the ground surface, deployed at approximately 700 locations nationwide [6].

In the main shock of 2011 Tohoku-oki Earthquake, 523 stations recorded. We choose those with peak ground motion acceleration (PGA) no less than 10gal, and the positions of 164 stations are shown in Fig.1. 
And, the sites of these stations are classified according to the ASCE Sta ndard ASCE/SEI 7-10 [7], the number of stations in each classification is shown in Fig.2.
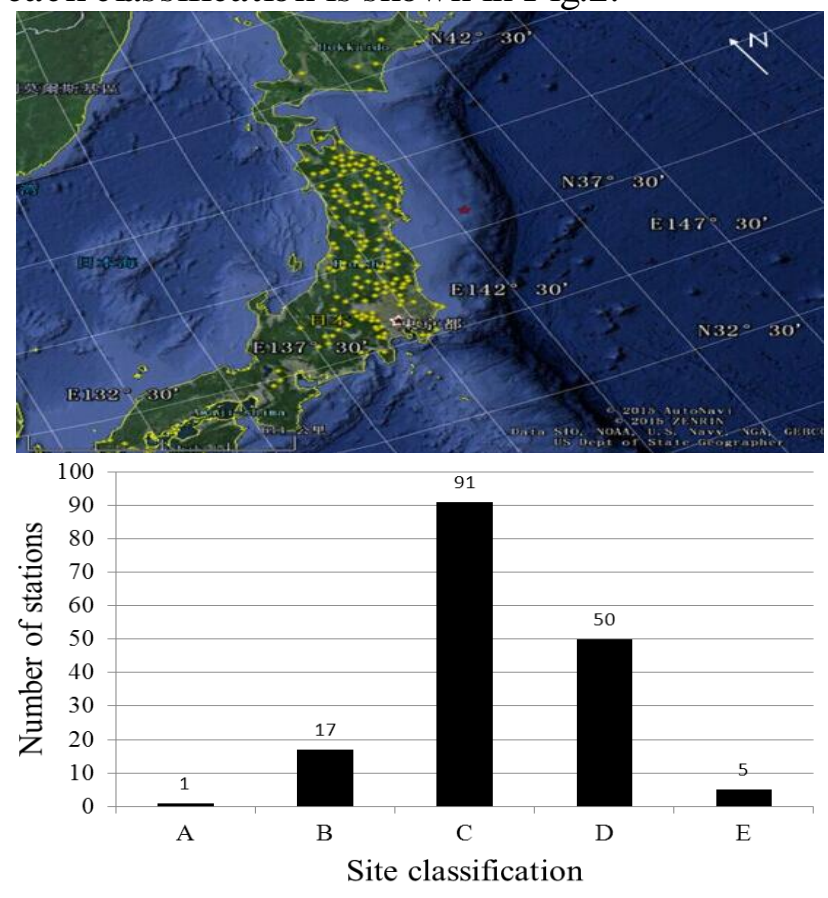

Fig. 1 The KiK-net stations position

Fig. 2 Number of stations in each site classification

On two horizontal directions, pairs of records in a borehole and on the surface are both adopted. For each record, the window is from the $S$ wave arrival to the time point with $80 \%$ of total energy accumulated. In addition, each record is dealt with $30 \mathrm{~Hz}$ low-pass filtering by the butterworth filter, since the total response characteristic is almost flat to $30 \mathrm{~Hz}$ [8].

We define the spectral ratio as the ratio of the Fourier spectrum of a surface record to that of a borehole record, the same with [5] and [9].

\section{Methodology}

The quarter-wavelength approximation method is to evaluate the frequency dependent site amplification. The approximation is insensitive to the velocity discontinuities beneath a site, and the method does not include the nonlinear response due to the different input intensities of seismic waves and the resonance due to subsurface topography [10].

From the velocity profiles of KiK-net station sites, thickness $\mathrm{h}(\mathrm{m})$ and shear wave (S wave) velocity of each layer $V_{S}(h)(m / s)$ is given, and the travel time of $S$ wave $S_{t t}(h)(s)$ can be calculated by

$$
S_{t t}(h)=\frac{h}{V_{S}(h)}
$$

The $S$ travel time from the surface to depth $z S_{t t}(z)(s)$ is the sum of $S_{t t}(h)$, then the average velocity to the depth $\mathrm{z}$ is

$$
\overline{V_{S}(z)}=\frac{Z}{S_{t t}(z)}
$$

The frequency to the depth $\mathrm{z} f(\mathrm{z})(\mathrm{Hz})$ is

$$
f(z)=\frac{1}{4 \times S_{t t}(z)}
$$


The amplification $\mathrm{A}[\mathrm{f}(\mathrm{z})]$ can be calculated by

$A[f(z)]=\sqrt{\frac{\rho_{s} \cdot V_{S}(s)}{\overline{\rho_{s}(z)} \cdot \overline{V_{S}(z)}}}$

where, $\rho_{\mathrm{s}}$ and $\mathrm{V}_{\mathrm{S}}(\mathrm{s})$ are the density and shear wave velocity around the source, given as $2.8 \mathrm{gm} / \mathrm{cc}$ and $3.5 \mathrm{~km} / \mathrm{s}$, respectively; $\overline{\rho_{s}(z)}$ and $\overline{V_{s}(z)}$ are the average density and shear wave velocity to the depth z.

The density is given as a function of shear velocity by the simple relation.

$\rho(z)= \begin{cases}2.5, & V_{S}(z)<0.3 \mathrm{~km} / \mathrm{s} \\ 2.5+\left[V_{S}(z)-0.3\right] \times \frac{2.8-2.5}{3.5-0.3}, & 0.3 \mathrm{~km} / \mathrm{s} \leq V_{S}(z) \leq 3 \mathrm{~km} / \mathrm{s}\end{cases}$

(5)

The site amplification factors of $164 \mathrm{KiK}$-net stations, at all frequencies, are shown in Fig.3.

In this figure, the amplification increases with the frequency decreases, which means it increases with the soil layer thickens.

The relation between the amplification factor $\mathrm{A}[\mathrm{f}(30)]$ and shear wave velocity to the depth of $30 \mathrm{~m}$ is shown in Fig.4.

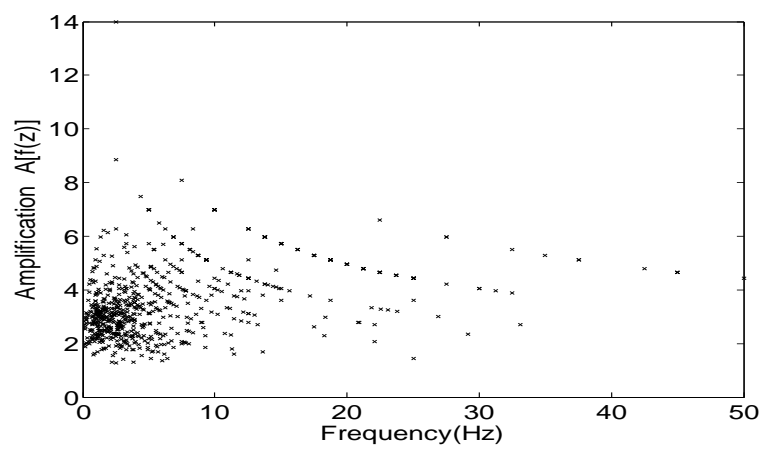

Fig. 3 Site amplification factors

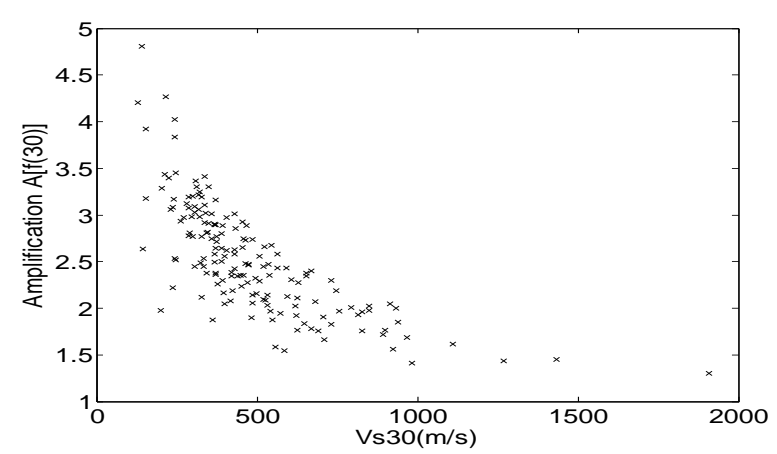

Fig. 4 Amplification factors with Vs30

As shown in Fig.4, the amplification increases with the average velocity decreases, that is, when the site soil layer is soft, the amplification is significant. This is obvious when we classify the sites, as shown in Fig.5 and Table I, the mean value of amplification factors is getting bigger from Class B to D.

The amplification factors $\mathrm{A}[\mathrm{f}(30)]$ for site Class B, C, D and E is shown in Fig.5.

The mean values and standard variations of amplification factors $\mathrm{A}[\mathrm{f}(30)]$ for these four classes of sites are listed in Table 1. 


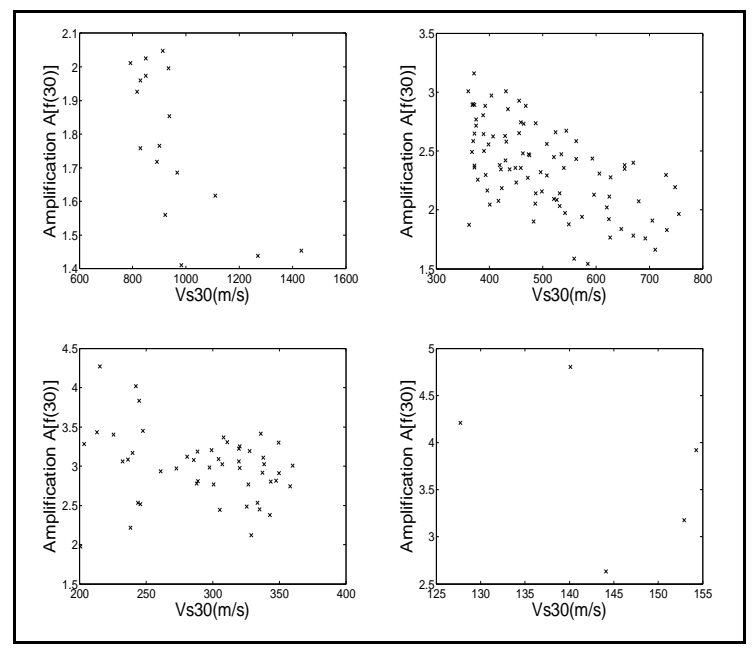

Tab. 1 Mean Values and Standard Variations of Amplification Factors

\begin{tabular}{|c|c|c|}
\hline \multirow{2}{*}{ Site Class } & \multicolumn{2}{|c|}{ Amplification Factor A[f(30)] } \\
\cline { 2 - 3 } & Mean value & Standard variation \\
\hline B & 1.776 & 0.2203 \\
\hline C & 2.354 & 0.3606 \\
\hline D & 2.996 & 0.4400 \\
\hline E & 3.747 & 0.8561 \\
\hline
\end{tabular}

Fig. 5 A[f(30)] for Class B, C, D and E

\section{Result Analysis}

To validate this approximation, observed records in section II is adopted to obtain the observed amplification, which is defined as the Fourier amplitude spectrum of the surface motion divided by that recorded in borehole.

The amplification factors from the quarter-wavelength approximation method are compared with those observed ones at the same frequency, which is shown in Fig.6.

The amplification factors from the quarter-wavelength approximation method are compared with those observed ones of PGAs, which is shown in Fig.7.
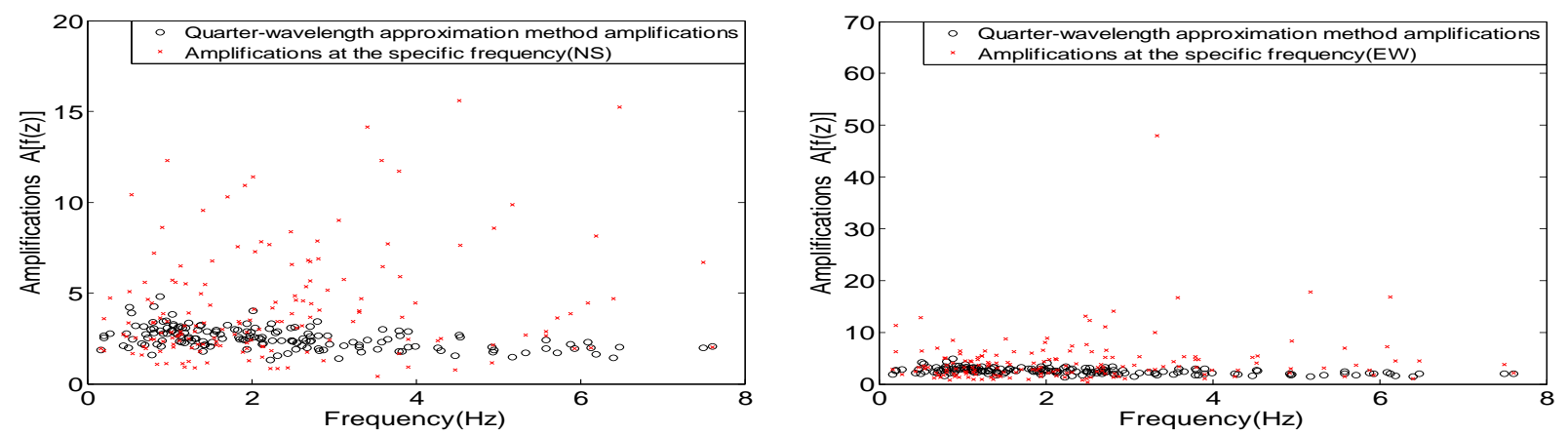

Fig. 6 Comparison of amplifications at the specific frequency
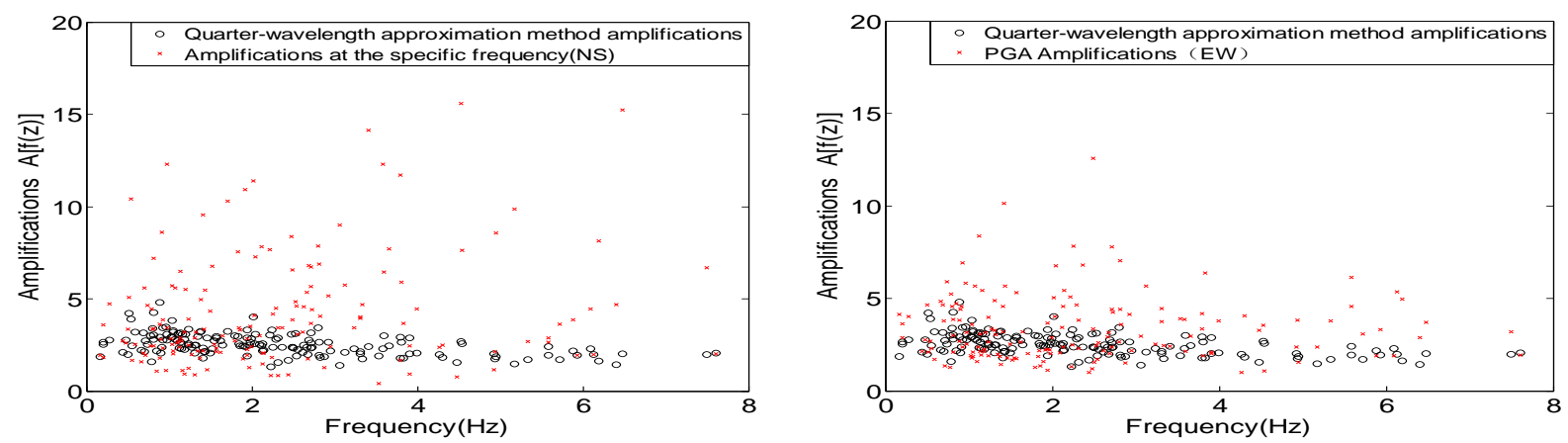

Fig. 7 Comparison of PGA amplifications 

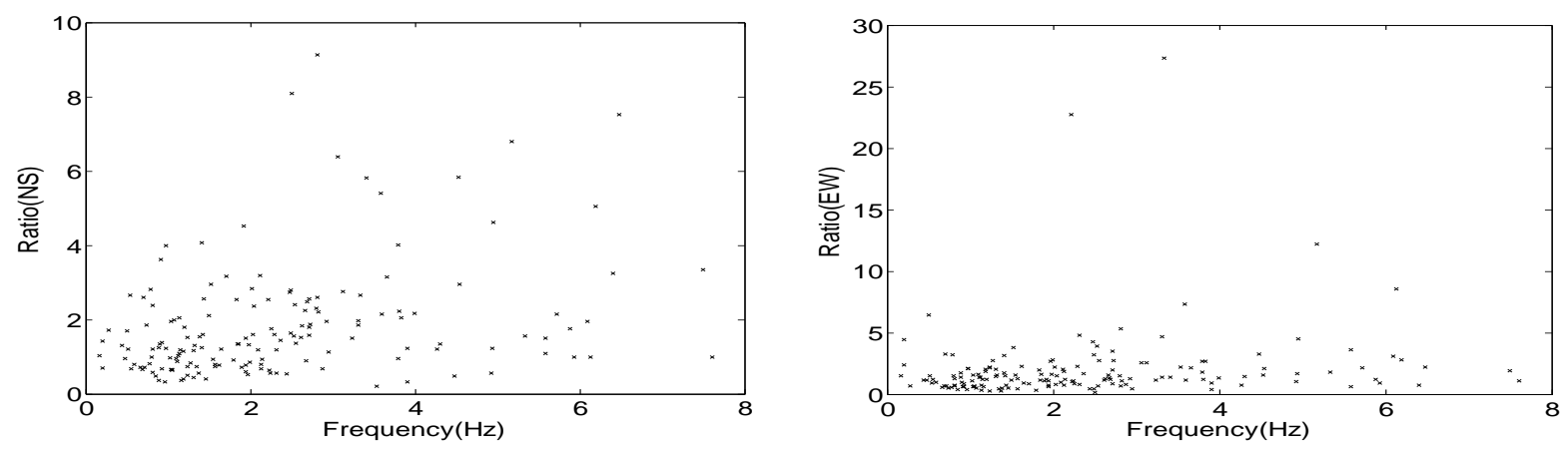

Fig. 8 Ratio of amplification factors at the specific frequency
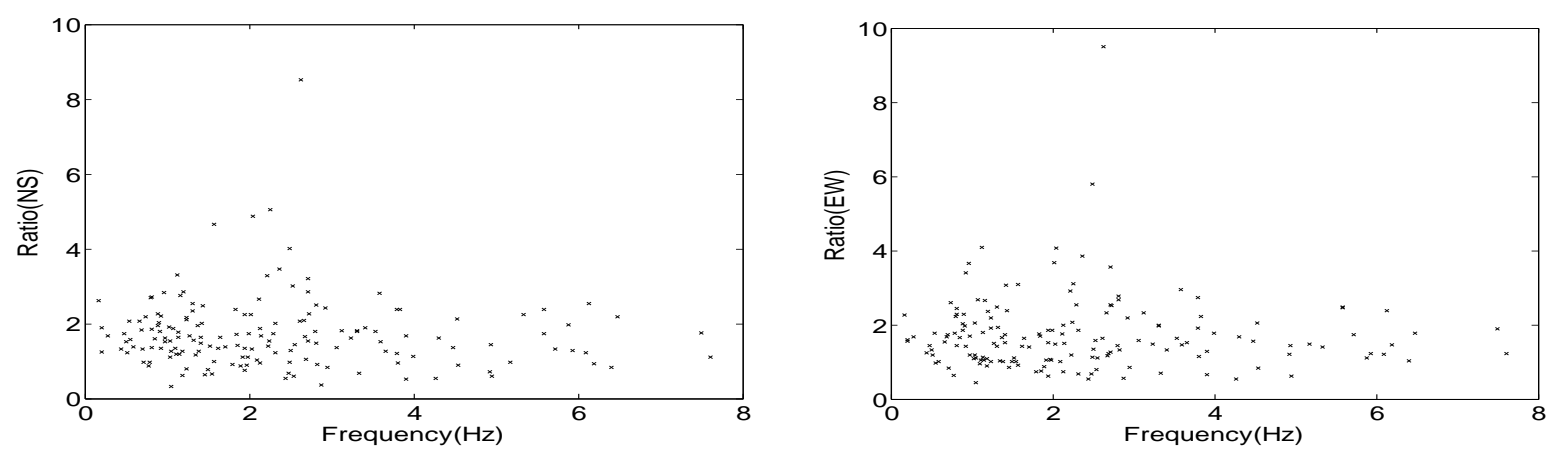

Fig. 9 Ratio of PGA amplification factors

To make the comparison clear, the observed amplification is divided by the calculated one.

From Fig. 6 to Fig.9, it is shown that most of the results from these two methods are close, the ratios are round 1. However, some amplification factors are larger, in both two directions or in one. The reason is complicated, like site condition, nonlinear response and down go ing wave effect etc. We will not discuss here, since the pages limitation.

\section{Conclusion}

The quarter-wavelength approximation to describe the site amplification is simple, which is validated by the records of $164 \mathrm{KiK}$-net stations, from the main-shock of 2011 Tohoku-oki Earthquake. The amplification decreases with frequency decreases. According to US seismic code, the station sites are classified. In Class A, there is only one data, which is not discussed further; in Class B, the mean value of amplification factors is 1.776 , standard variation is 0.2203 ; in Class $\mathrm{C}$, the mean value is 2.354, standard variation is 0.3606; in Class D, the mean value is 2.996, standard variation is 0.44 ; in Class $\mathrm{E}$, the mean value is 3.747 , standard variation is 0.8561 . The amplification is significant if the site is soft.

The calculated amplification, by the quarter-wavelength approximation, is compared with the observed amplification in this event. Most results are close, however, it is preliminary. Ratios of amplification factor at the specific frequency on the north-south direction are less than 10; on east-west direction, there are three points more than 10. Those of PGA amplification factors are less than 10 on both horizontal directions. Some amplification factors by quarter-wavelength approximation are less than the observed ones. The reason of this gap is complicated, including soil properties and nonlinear response etc.

\section{References}

[1] R.D. Borcherdt, Effects of local geology on ground motion near San Francisco Bay, Bull. Seismol. Soc. Am., 60 (1970) 29-61. 
[2] Y. Nakamura, A method for dynamic characteristics estimation of subsurface using microtremor on the ground surface, Railway Technical Research Institute, Quarterly Reports, 30 (1989) 25-33.

[3] B. Edwards, C. Michel, V. Poggi, and D. Fäh, Determination of site amplification from regional seismicity: application to the Swiss National Seismic Networks, Seismol. Res. Lett., 84, 4 (2013) 611-621.

[4] W.B. Joyner, R.E. Warrick, and T.E. Fumal, The effect of Quaternary alluvium on strong ground motion in the Coyote Lake, California, earthquake of 1979, Bull. Seism. Soc. Am., 71 (1981) 1333-1349.

[5] D.M. Boore and W.B. Joyner, Site amplifications for generic rock sites, Bull. Seism. Soc. Am., 87, 2 (1997) 327-341.

[6] Information on http://www.kyoshin.bosai.go.jp/kyoshin/docs/overview_kyoshin_index_en.html

[7] American Society of Civil Engineers, Minimum design loads for buildings and other structures, ASCE Standard ASCE/SEI 7-10. Reston, Virginia, US. (2010)

[8] S. Aoi, T. Kunugi, H. Nakamura, and H. Fujiwara, Deployment of new strong motion seismographs of K-NET and KiK-net, Earthquake Data in Engineering Seismology, (2011) 167-186.

[9] C. Héloïse, P.Y. Bard, and R.M. Adrian, Site effect assessment using KiK-net data: Part 1. A simple correction procedure for surface/downhole spectral ratios, Bull. Earthquake. Eng., 10 (2012) 421-448.

[10] M.W. Huang, J.H. Wang, H.H. Hsieh, K.L. Wen, and K.F. Ma, Frequency-dependent sites amplifications evaluated from well-logging data in central Taiwan, Geophys. Res. Lett., 32 (2005) L21302. 